\title{
Effect of Cognitive-Behavioural Group Guidance on Entrepreneurial Intention Among University Sandwich Education Students
}

\author{
Mkpoikanke Sunday Otu ${ }^{1}$, Mabel A. Obidoa ${ }^{1}$, Shulamite E. Ogbuabor ${ }^{1}$, Lilian Chijioke Ozoemena ${ }^{1}$, \\ Gabriel Ochaka Okpanachi ${ }^{1}$, Patience Nwobodo ${ }^{1}$, Chinenye Ifeoma Ogidi ${ }^{1}$, Benedeth Lebechi Ugwu ${ }^{1}$, \\ Chisom E. Egwim ${ }^{1} \&$ Favour Mkpoikanke Otu ${ }^{1}$ \\ ${ }^{1}$ Department of Educational Foundations, Faculty of Education, University of Nigeria, Nsukka, Nigeria \\ Correspondence: Shulamite E. Ogbuabor, Department of Educational Foundations, Faculty of Education, \\ University of Nigeria, Nsukka, P.M.B. 410001, Enugu State, Nigeria. E-mail: shulamite.ogbuabor@unn.edu.ng
}

Received: May 12, 2019 Accepted: June 15, 2019 Online Published: June 27, 2019

doi:10.5539/gjhs.v11n8p80 URL: https://doi.org/10.5539/gjhs.v11n8p80

\begin{abstract}
Objective: The study objective was to determine the effects of cognitive-behavioural group guidance on entrepreneurial intention among university sandwich education students.

Materials and Method: The design of the study was a group randomized trial involving pretest and posttest, while the area of the study was a federal university in South-East Nigeria. Entrepreneurial Intention Questionnaire (EIQ) was used for data collection while the data collected were analysed through analysis of covariance with repeated measures.

Results: The results indicated that there was no significant difference between the participants' entrepreneurial intention in the treatment and no-treatment control groups at the initial measure; and that after cognitive-behavioural group guidance intervention, there was a significant increase in entrepreneurial intention among the participants in the treatment group comparing to their counterparts in the no-treatment control group.

Conclusion: Cognitive-behavioural group guidance was effective in increasing entrepreneurial intention among university sandwich education students. It was therefore concluded that counsellors should adopt the techniques used in the study to help individuals increase their entrepreneurial intention, and that cognitive-behaviour group guidance should be adopted as counselling approach for helping university students develop intentions to venture into entrepreneurial business.
\end{abstract}

Keywords: cognitive-behavioural, entrepreneurial business, university students

\section{Introduction}

Despite the high rate of unemployment in society today, it seems like many young individuals are not willing to get into entrepreneurship. Entrepreneurship is the totality of self-asserting attributes that enable a person to identify business opportunities, organize the needed resources and determines to undergo risks and uncertainties (Essien, 2006). Thus, entrepreneurship involves identifying interest, passion, potentials and opportunity in an environment. According to Arunwa (2004) entrepreneurship requires the education which equips the learners with the skills, ideas, attitude to make a mature judgment and to be in the position to create goods and services. But it seems that the education given at the various tertiary institutions in Nigeria and other developing countries has not made graduates self-reliant in creating jobs for themselves and others. However, there is increasing evidence that Nigerian university students are lacking entrepreneurial intention due to numerous factors influencing such intention (Ekpoh \& Edet, 2011; Muhammad, Aliyu, \& Ahmed, 2015). Hence, the rate of graduates who are not employed in Nigeria is still high despite all the effort made by the federal government to provide jobs for the youths. Meanwhile, the challenge of unemployment can be resolved if the graduates develop entrepreneurial intention. The entrepreneurial intention involves thinking that emphasizes opportunities over threats.

Bhaskar and Garimella (2017), conducted a study on predictors of entrepreneurial intentions and found that the challenges faced by masters students of business administration appear to be a major reason to become an entrepreneur, followed by ambition, financial gain, comfort and opportunity to help others. Gorgievski, Stephan, Laguna and Moriano (2017) investigated the mechanisms through which individual values are related to entrepreneurial career intentions and found that openness and self-enhancement values relate positively to 
entrepreneurial intentions. Almeida, Ahmetoglu, and Chamorro-Premuzic (2014) earlier conducted a study to investigate associations between vocational interests, entrepreneurial potential, and entrepreneurial activity, both within and outside organizations, and found that vocational interests predict entrepreneurial activity even when entrepreneurial potential and demographic variables are taken into account. However, the process of identifying opportunities is plainly an intentional process, and, therefore, entrepreneurial intentions are important for the implementations of entrepreneurship (Krueger, Reilly, \& Carsrud, 2000). There is evidence that a variety of intention models have been developed. However, Peterman and Kennedy (2003) indicated that some models of entrepreneurial intention focus on the pre-entrepreneurial event and make use of attitude and behaviour theory (Ajzen, 1991), and self-efficacy and social learning theory (Bandura, 1997). Other studies present entrepreneurial intention as a variable within larger psychological models (Davidsson, 1995). Thus, intentional elements, such as expectations, attention, and belief, appear to have a strong impact on people's behaviour.

In line with the previous evidence, the researchers of the current study determined the effect a cognitive-behavioural group guidance programme could have on entrepreneurial intention among students. Cognitive-behavioural group guidance programme was developed by the principal researcher to help the participants develop entrepreneurial intention. The programme was informative, educative and therapeutic, and designed based on the principle of cognitive-behavioural coaching (CBC). The core principle of CBC is that people may have insufficient problem-solving skills or may not use their skills in a contextually suitable way, and that peoples' thoughts, emotions, and behaviours are keys to understanding their perception of problems and situations (Onyechi et al., 2016; Eseadi et al., 2017). The cognitive-behavioural group guidance could enable the individuals to acquire positive thoughts, emotions and behaviours that support entrepreneurship. In addition, the cognitive-behavioural group guidance can help individuals to identify, examine, and change unhealthy thoughts and beliefs, develop productive behaviours, become more interested in entrepreneurship (Gladeana, 2016). The research focused on university sandwich students because they stand at one of life's vantage points, one at which they think about careers. It is an appealing setting from the basic and the applied research points-of-view (Shinnar et al., 2009). To this end, the prime focus of cognitive-behavioural group guidance was on the participant's current concerns and the ultimate goal was for the participants to be able to handle their own present and future entrepreneurial challenges. Thus, the researchers hypothesized that cognitive-behavioural group guidance will be effective in increasing entrepreneurial intention among university sandwich education students.

\section{Method}

\subsection{Ethical Compliance}

The researchers complied strictly with the ethical standards for conducting research with human subject set by the American Psychology Association and the Research Ethics Committee of the Faculty of Education, University of Nigeria, Nsukka.

\subsection{Design of the Study}

The design used for the study was a group randomized trial.

\subsection{Area of the Study}

The study was carried out in a federal university in South-East Nigeria.

\subsection{Sample and Sampling Technique}

The sample of the study was 250 final year university sandwich education students from a federal university in South-East Nigeria. The sample was selected through purposive and voluntary sampling. Out of the 250 students who volunteered to participate in the study, 89 students met the study's inclusion criteria, which include: being ready and willing to attain all the sessions of the study; having a low entrepreneurial intention, and being able to speak English Language fluently (See Figure 1).

\subsection{Procedure}

The researchers used one month to create awareness for the cognitive-behavioural group guidance programme. The researchers also talked to the students about the importance of attending the programme and encouraged them to participate in the programme. Interested participants were requested to give their informed consent and register with their class representatives. The 89 students who met the inclusion criteria in the study were randomized into two groups -experimental $(n=44)$ and no-treatment control group $(n=45)$. The $\mathrm{G}^{*}$ Power 3.1.1 statistical software and computer-generated numbers were used in the randomization process. Both participants at the experimental and no-treatment control group were exposed to pretest measure.

Thereafter, the participants in the experimental group were made to attend cognitive-behavioural group guidance 
programme while the participants in the no-treatment control group did not attend any guidance programme within the period of the study. After the cognitive-behavioural group guidance programme, the researchers conducted posttest measure in the two groups. All the data collected at the pretest and posttest measures were subjected to analysis by expert data analysts who did not take part in intervention and assessment processes.

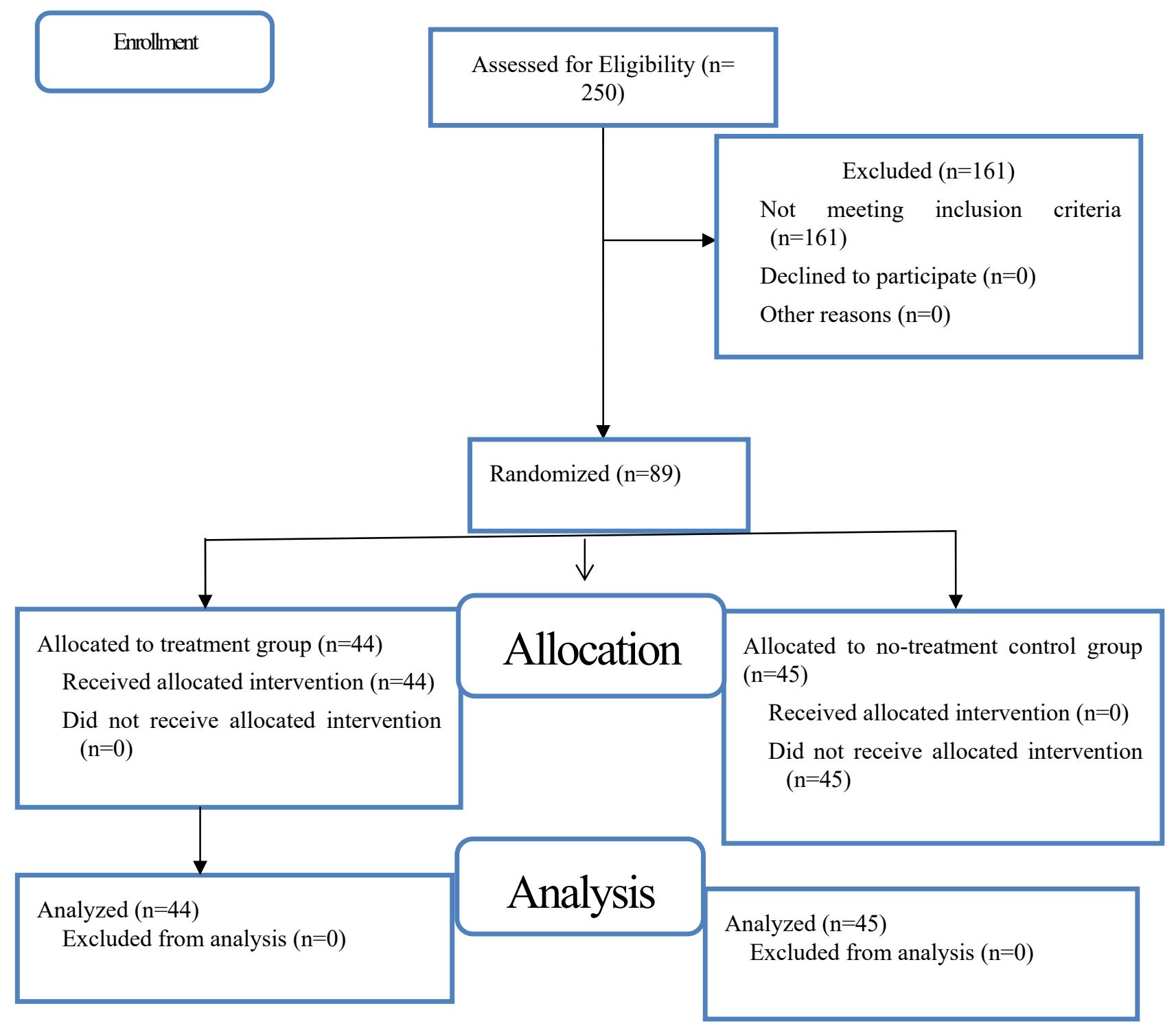

Figure 1. Flow Chart

\subsection{Intervention}

Cognitive-Behavioural Group Guidance: The cognitive-behavioural group guidance was designed to increase the participants' entrepreneurial intention. The intervention programme was implemented in three phases. The first phase of the programme featured entrepreneurship education which was anchored by experts in vocational and business education. The entrepreneurship education covers direct teaching on the general concept of entrepreneurship; how to start a business, how to manage a business; barriers to business establishment and how to deal with them; different types of business and how to raise fund for business. In addition, the facilitators exposed the participants to certain business opportunities which they can start with little income such as soap making, cream making, water production, food production/processing, international business agency service, laundry, agricultural production/processing, transportation, exportation and importation, among others. The facilitators also discussed networking opportunities with the participants and encourage the interested ones to indicate interest for subsequence follow up. Also, the facilitators enlightened the participants on the availability and accessibility of business fund from various national and international agencies. Also, the participants were given opportunities to 
ask questions and get clarifications. The second phase of the cognitive-behavioural group guidance featured group guidance intervention anchored by professional counsellors who were experts in cognitive-behaviour coaching/therapy $(\mathrm{CBC} / \mathrm{T})$. The focus of the second phase of the programme was to help the participants acquire positive thoughts, emotions and behaviours that support entrepreneurship. In line with previous evidence (Onyechi et al., 2016), strategies and techniques such as goal setting, motivational interviewing, cognitive restructuring, and coping imagery were used by the counsellors to confront the psychological blocks to entrepreneurial intention and reducing unsupportive emotions. The last phase featured practical skill training on liquid soap making and hair cream production. The aim of this phase was to demonstrate the reality of venturing into a small production business that requires little materials and fund. The demonstrations were facilitated by four experts among the researchers. The participants were made to practically learn how liquid and hair cream is being produced. The participants wrote the production tips -in terms of steps to follow, materials to use, how to measure the materials and other procedures, among others. The participants asked questions for clarification and practiced the skills after a period of learning.

\subsection{Measure}

Entrepreneurial Intention Questionnaire (EIQ): The EIQ had 18 items developed by the principal researcher based on a four-point scale of strongly agreed (4 points), agreed ( 3 points), disagreed ( 2 points) and strongly disagreed (1 point). The EIQ had a reliability coefficient of 0.84 alpha in the current study.

\subsection{Data Analysis}

The ANCOVA with repeated measures was used to analyse data in the current study. The ANCOVA was used to compare one or more mean scores with each other and tests for the significant difference in mean scores. Partial Eta Squared was used to determine the effect size of the intervention. In line with Cohen's method for interpreting effect size of an intervention(Cohen, 1988), value of 0.00-0.19 indicated very small effect size, 0.20-0.49 indicated small effect size, and 0.50-0.79 indicated medium effect size while 0.80 and above implied large effect size.

\section{Results}

Table 1. Results on the Effect of Cognitive-Behavioural Group Guidance on Entrepreneurial Intention among University Sandwich Education Students by EIQ

\begin{tabular}{lllllllll}
\hline Assessment & Measures & Group & Mean(SD) & $\mathbf{F}$ & Sig. & $\eta_{p}^{L}$ & $\Delta \mathbf{R}^{\mathbf{2}}$ & $\mathbf{9 5 \%} \mathbf{C I}$ \\
\hline Pretest & EIQ & Treatment & $18.26(1.26)$ & .112 & .738 & .001 &.-010 & $18.59-19.36$ \\
& & Control & $19.06(1.25)$ & & & & & $18.69-19.44$ \\
\multirow{3}{*}{ Posttest } & \multirow{2}{*}{ EIQ } & Treatment & $62.54(4.89)$ & 3285.31 & .000 & .974 & .974 & $61.05-64.03$ \\
& & Control & $19.06(1.38)$ & & & & & $18.64-19.48$ \\
\hline
\end{tabular}

EIQ: Entrepreneurial Intention Questionnaire; M: Mean; SD: Standard Deviation; $\eta_{p}^{<}:$Effect size; df: Degree of Freedom; Sig: Significant value.

From Table 1, the researchers observed that there was no significant difference between the entrepreneurial intention of participants in the treatment and no-treatmentcontrol groups, $F(1,88)=.738, P=.789, \eta_{p}^{2}=.001$, $\Delta \mathrm{R}^{2}=$.-010. After cognitive-behavioural group guidance intervention, it was observed that there was a significant increase in entrepreneurial intention among the participants in the treatment group, comparing to their counterparts in the no-treatment control group, $F(1,88)=3285.31, P=.000, \eta_{p}^{2}=.974, \Delta \mathrm{R}^{2}=.974$. Based on the results, it was observed that cognitive-behavioural group guidance was effective in increasing entrepreneurial intention among university sandwich education students. 


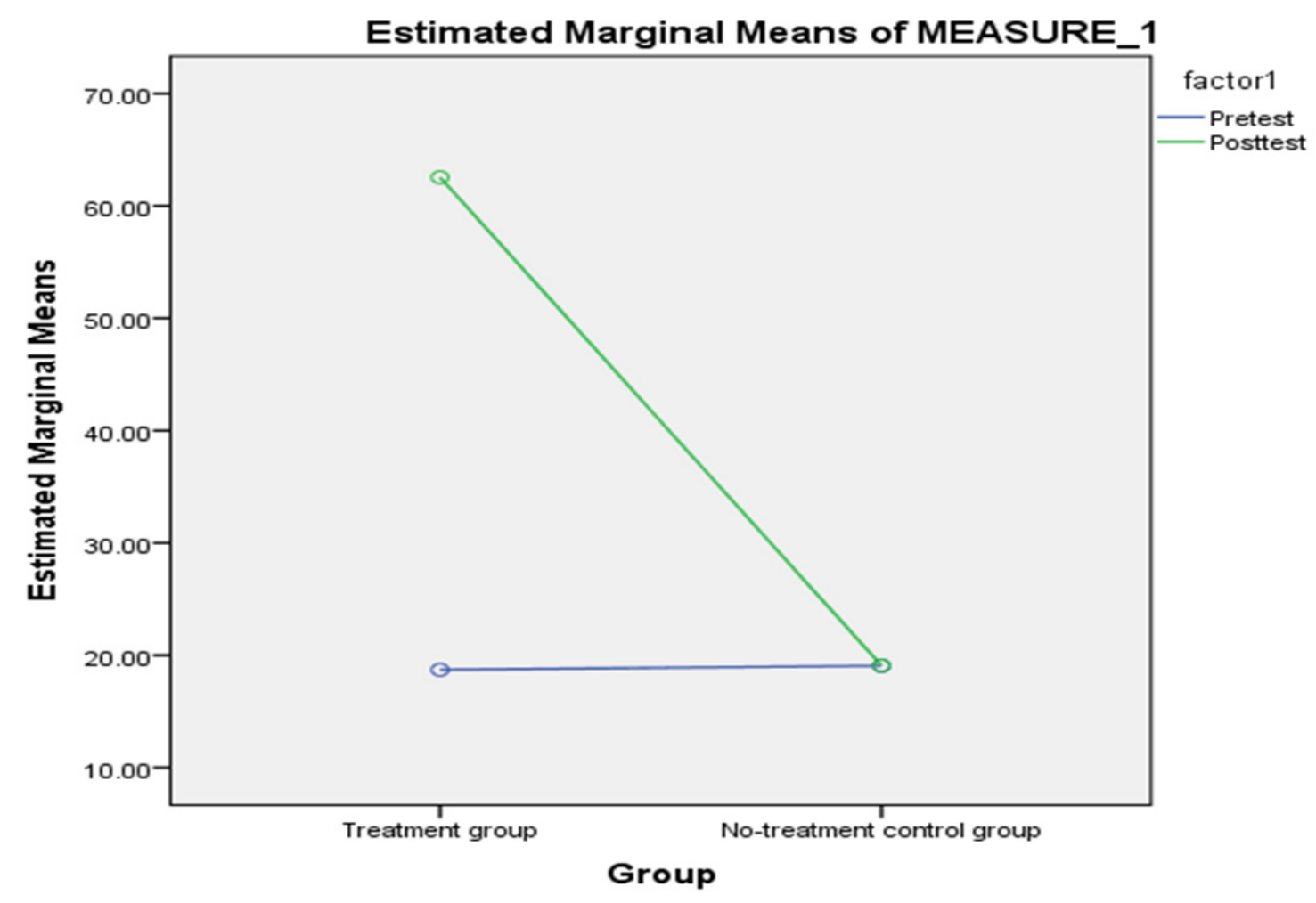

Figure 2. Estimated marginal mean

\section{Discussion}

The objective of the study was to determine the effect of cognitive-behavioural group guidance on entrepreneurial intention among university sandwich education students. The initial measure showed no significant difference between the participants' entrepreneurial intention in the treatment and no-treatmentcontrol groups. This finding supports previous studies that Nigerian university students are increasingly lacking entrepreneurial intention (Ekpoh \& Edet, 2011; Muhammad, Aliyu, \& Ahmed, 2015). After cognitive-behavioural group guidance intervention, there was a significant increase in entrepreneurial intention among the participants in the treatment group comparing to their counterparts in the no-treatment control group. The finding supports the previous prediction that intervention that has the cognitive-behavioural components could effectively increase entrepreneurial intention among individuals.

The low rate of entrepreneurial intention among Nigerian university students may have contributed to the high rate of unemployment in Nigeria. Therefore, if cognitive-behavioural group guidance is to be utilized adequately many Nigerians could acquire high intention to venture into entrepreneurship. Again, there is a need for researchers in Nigeria and other parts of the world to replicate the study in different settings in order to validate or invalidate the findings generated in the study. If more studies validate the current findings, it would be necessary for cognitive-behavioural group guidance intervention to be adopted as the best approach for increasing entrepreneurial intention among individuals.

\subsection{Limitation}

Despite the findings, some limitations were recorded. First, the sample of the study comprised of only sandwich education students. It would be better for subsequent studies to include other categories of university students. Secondly, the demographic information of the participants is missing in the study. Future studies should endeavour to describe and analyze demographic information of the participants. The third limitation of the findings is that qualitative research data is missing in the results. It may be good for future researchers to consider reporting the results of both qualitative and quantitative data. Lastly, one may argue that the sample size was too small in the study. However, the researchers of the current study suggest that subsequent versions of the study should increase the sample size to at least 300 . 


\section{Conclusion}

The researchers of this study conclude that cognitive-behaviour group guidance was effective to increase entrepreneurial intention among Nigerian university sandwich education students. Therefore, counsellors should adopt the techniques used in the study to help individuals increase their entrepreneurial intention. Also, cognitive-behaviour group guidance should be adopted as a counselling approach for helping university students develop intentions to venture into an entrepreneurial business.

\section{Competing Interests Statement}

The authors declare that there are no competing or potential conflicts of interest.

\section{Funding}

The researchers did not receive grant or financial aid from any government or individual donor.

\section{References}

Ajzen, I. (1991). Theory of planned behaviour.Organizational Behaviour and Human Decision Processes, 50, 179-211. https://doi.org/10.1016/0749-5978(91)90020-T

Bandura, A. (1997). Self-efficacy: toward a unifying theory of behavioural change. Psychological Review, 84, 191-215. https://doi.org/10.1037/0033-295X.84.2.191

Cohen, J. (1988). Statistical Power Analysis for the Behavioral Sciences (2nd ed.). Hillsdale, NJ: Lawrence Erlbaum Associates, Publishers.

Davidsson, P. (1995). Determinants of entrepreneurial intentions. Paper presented at the RENT IX Workshop in Entrepreneurship Research, November 23-24, Piacenza, Italy.

Ekpoh, U. I., \& Edet, A. O. (2011). Entrepreneurship education and career intentions of tertiary education students in Akwalbom and Cross River States, Nigeria. International Education Studies, 4(1), 172-178. https://doi.org/10.5539/ies.v4n1p172

Eseadi, C., Obidoa, M. A., Ogbuabor, S. E., \& Ikechukwu-Ilomuanya, A.B. (2017). Effects of group-focused cognitive-behavioral coaching program on depressive symptoms in a sample of inmates in a Nigerian prison. International Journal of Offender Therapy and Comparative Criminology, 62(6), 1589-1602. https://doi.org/10.1177/0306624X16687046

Gladeana, M. (2016). Cognitive Behavioral Coaching Works! Retrieved June 26, 2016, from http://www.cognitivebehaviouralcoachingworks.com/

Neenan, M. (2018). From cognitive behaviour therapy (CBT) to cognitivebehaviour coaching (CBC).Journal of Rational-Emotive Cognitive-Behaviour Therapy, 26(1), 3-15. https://doi.org/10.1007/s10942-007-0073-2

Onyechi, K. C. N., Eseadi, C., Okere, A. U., Onuigbo, L. N., Umoke, P. C., Anyaegbunam, N. J., . . \& Ugorji, N. J. (2016). Effects of cognitive behavioral coaching on depressive symptoms in a sample of type 2 diabetic inpatients in Nigeria. Medicine, 95(31), e4444. https://doi.org/10.1097/MD.0000000000004444

Palmer, S., Szymanska K., Palmer S., \& Whybrow A. (2008). Cognitive behavioral coaching: an integrative approach. Handbook of Coaching Psychology: A Guide for Practitioners (pp. 86-117). New York, NY: Routledge/Taylor \& Francis Group.

\section{Copyrights}

Copyright for this article is retained by the author(s), with first publication rights granted to the journal.

This is an open-access article distributed under the terms and conditions of the Creative Commons Attribution license (http://creativecommons.org/licenses/by/4.0/). 